\title{
EL CONJUNTO DE CANGAS DE ONÍS: ARQUEOLOGÍA DEL ORO CASTREÑO ASTURIANO
}

\author{
CANGAS DE ONÍS: THE ARCHAEOLOGY OF CASTRO GOLD IN ASTURIAS
}

ÓSCAR GARCÍA VUELTA $\left(^{*}\right)$

\section{RESUMEN}

Presentamos la revisión de uno de los conjuntos más significativos de la orfebrería de la II Edad del Hierro en el Norte y Noroeste peninsular, el conocido como procedente de Cangas de Onís (Oviedo, Asturias), conservado en el Museo Arqueológico Nacional. La realización de un nuevo análisis tecnológico y documental de cada una de sus piezas nos ha permitido aportar nuevos datos para su estudio, así como plantear algunas hipótesis explicativas que entran en contradicción con la historiografía tradicional.

\begin{abstract}
We present a revision of one of the most important II Iron Age finds from the North and Northwest Iberian Peninsula Goldwork from Cangas de Onís (Asturias, Oviedo, Spain), keep in the National Archaeological Museum. The new technological and documentational analysis of each of these pieces allows us to propose hypotheses that are inconsistant with the traditional historiography.
\end{abstract}

Palabras clave: Orfebrería castreña. Torques. Oro. Diademas-cinturón. II Edad del Hierro.

Key words: Castro culture goldwork. Torcs. Gold. Diadems-belt. II Iron Age.

\section{INTRODUCCIÓN}

La carencia de revisiones actualizadas del material arqueológico es un problema que afecta a gran

(*) Dpto. de Prehistoria, IH, CSIC. Serrano 13. 28001. Madrid. Correo electrónico: ovuelta@ceh.csic.es

Este artículo fue remitido en su versión final el 28-III-2001. Fotografías: Oscar García Vuelta. parte de la orfebrería castreña, muchas piezas y conjuntos son aún objeto de trabajos que no se apoyan en una observación directa de las piezas, validando un buen número de opiniones insuficientemente fundadas sobre su procedencia y técnicas de fabricación. Este inconveniente, junto a otros, ha contribuido a un largo estancamiento de la investigación en esta materia (Balseiro, 1999).

A pesar de esto, las últimas labores de síntesis han permitido plantear nuevos puntos de vista sobre la orfebrería castreña a partir del análisis tecnológico de sus materiales (Perea y Sánchez-Palencia, 1996; Armbruster y Perea, 2000). Este trabajo, centrado en la región asturiana, supone una nueva aportación en esta línea, defendiendo la utilidad del análisis técnico y tecnológico de los materiales como metodología de estudio e incidiendo además en la necesidad básica de sistematizar toda la información disponible sobre las piezas como paso previo a su adecuado análisis y caracterización (1).

Para esto, hemos elegido como ejemplo uno de los conjuntos más controvertidos de la orfebrería castreña en la región asturiana, el grupo de piezas de oro con procedencia supuesta en Cangas de Onís (Oviedo, Asturias). Este lote, que tradicionalmente se viene interpretando como un único hallazgo, se compone de siete fragmentos de torques y una diadema-cinturón. Estos materiales se conservan desde 1931 en el Museo Arqueológico Nacional (M.A.N.) de Madrid y pertenecieron anteriormente

(1) Este trabajo se incluye en el Proyecto de Investigación "Tecnología, metalurgia y valor en la orfebrería castreña de los museos de Madrid" (exp. 06/0090/2000), financiado por la Comunidad de Madrid. Agradecemos el apoyo del Dpto. de Protohistoria y Colonizaciones del M.A.N, que dio todo tipo de facilidades para el estudio del material. Queremos agradecer también al Archivo Documental, Gabinete Numismático y Dpto. de Restauración del M.A.N. su apoyo durante el estudio documental y topográfico de las piezas. 


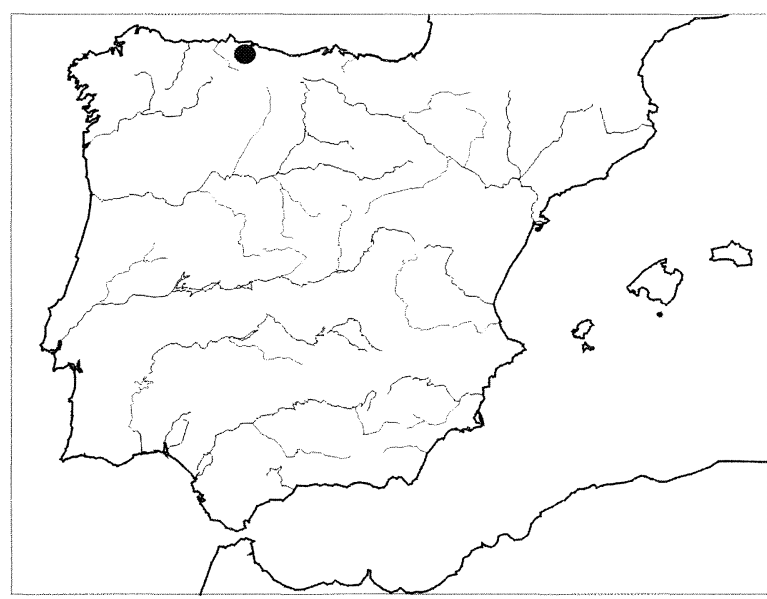

Fig. 1. Situación geográfica supuesta de las piezas.

a la colección Soto Cortés, ubicada en Labra, localidad próxima a Cangas de Onís (Álvarez-Ossorio, 1931 y 1954; López Cuevillas, 1951 a; Diego Somoano, 1960 a; Maya, 1987-1988).

Desde el punto de vista arqueológico, los problemas planteados por estas piezas son numerosos; desconocemos las circunstancias, lugar y momento de su recuperación y apenas contamos con información para determinar su contexto y asociaciones. Debido a ello, la mayor parte de los estudios que se han ocupado de estos materiales lo han hecho de forma indirecta, recogiendo los datos proporcionados por los primeros trabajos publicados tras su adquisición (Álvarez-Ossorio, 1931).

Aunque hay que poner en duda tanto la procedencia tradicionalmente asignada a las piezas como su naturaleza de conjunto, estos materiales son representativos de las técnicas y tipos característicos de la metalurgia del oro de la II Edad del Hierro en el Norte y Noroeste peninsular. Su análisis detallado permite, además, apuntar interesantes datos acerca de los modos de producción y la tecnología de los orfebres castreños.

\section{CATÁlogo}

a) Torques con varilla de sección cuadradaromboidal con estrías y un terminal hueco, decorado, en doble escocia. Inventario 33.132 (Lám. I, A): su aro, macizo, presenta forma de $\mathrm{C}$ adelgazada hacia los extremos y cuatro líneas longitudinales en sus dos caras exteriores, a lo largo de todo su desarrollo (Lám. II). Los terminales se fabricaron en cuatro partes, unidas por soldadura. Conserva- mos uno completo, que incluye un elemento de sonajero en su interior y decoración de motivos geométricos realizada por estampado, con un botón central esférico en su placa frontal. Conservamos además la placa posterior de un segundo terminal, en esta parte de los remates observamos la soldadura de un alambre de sección plano-convexa rodeando el orificio de entrada de la varilla.

- Dimensiones y peso: diámetro máx.: $18 \mathrm{~cm}$; grosor máximo del aro: $1,1 \mathrm{~cm}$; grosor mínimo: 0,7 $\mathrm{cm}$. Longitud del terminal: $3,9 \mathrm{~cm}$; diámetro máximo: $3,1 \mathrm{~cm}$. Diámetro placa frontal: $2,5 \mathrm{~cm}$; diámetro placa posterior: $2,5 \mathrm{~cm}$. Pesa $203 \mathrm{~g}$.

b) Restos de torques decorado, con alambre enrollado y remates en doble escocia. Inventario: 33.133 (Lám. I, B), 33.137 y 33.138 (Lám. I, F y $\mathrm{G})$ : estos tres fragmentos, un tramo de aro (33.133) y dos terminales (33.137 y 38 ), pertenecen a un torques con alma interior de plata de perfil rectangular, que se ornamentó en tres secciones, alternando un tramo central de lámina con decoración geométrica en bandas longitudinales con dos tramos laterales de alambres enrollados, de los que conservamos parte de uno (2). El tercio central se fabricó a la cera perdida y quedó delimitado a ambos lados por dos placas con figuración de doble espiral e imitación de granulado, elaboradas con la misma técnica.

Los terminales son huecos y se fabricaron en cuatro partes, fundidas y soldadas entre sí. Sus placas frontales y posteriores reciben decoración geométrica y se fabricaron a la cera perdida. El n. ${ }^{\circ}$ 33.137 conserva aún restos del aro (Lám. III).

- Dimensiones y peso: El fragmento 33.133 presenta un desarrollo de $155 \mathrm{~mm}$, su grosor máximo es de $1,1 \mathrm{~cm}(1,35 \mathrm{~cm}$ en zona de espirales) y el mínimo de $0,8 \mathrm{~cm}$. Grosor de la espiral conservada $0,2 \mathrm{~cm}$; Anchura del alambre enrollado hueco: $0,4 \mathrm{~cm}$. Pesa $145 \mathrm{~g}$.

Los terminales tienen una altura de $4,8 \mathrm{~cm}$; diámetro de las placas frontales: $2,8 \mathrm{~cm}$; diámetro botón central: $0,35 \mathrm{~cm}$; diámetro placas posteriores: $3,1 \mathrm{~cm}$; diámetro máximo: $3,4 \mathrm{~cm}$. Anchura de los alambres del resto de varilla en el terminal $n .^{\circ}$

(2) Aunque se ha discutido sobre esta asociación de fragmentos, el estudio de estos materiales y los últimos datos que recientemente hemos podido consultar, procedentes de los archivos de la colección Soto Cortés, apuntan claramente que los tres que conservamos, a los que habría que sumar otro hoy desaparecido, pertenecerían a un mismo torques. Agradecemos a $\mathrm{D}^{\mathrm{a}}$ María Teresa Pendás el acceso a tan valiosa información.

T. P., 58, n. ${ }^{\circ} 2,2001$ 

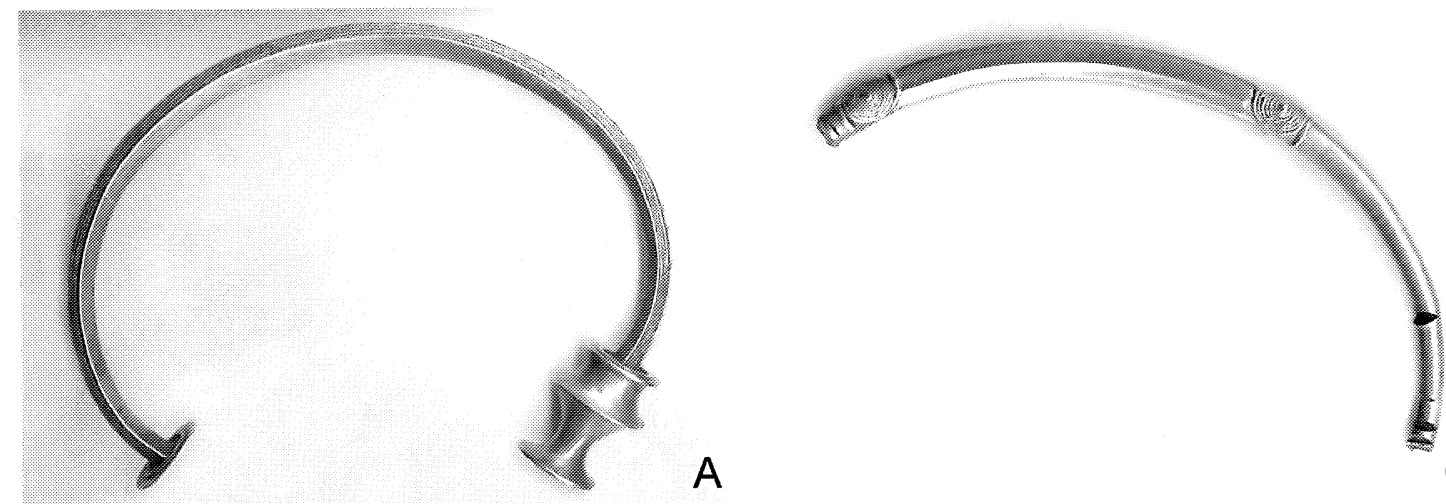

A

C

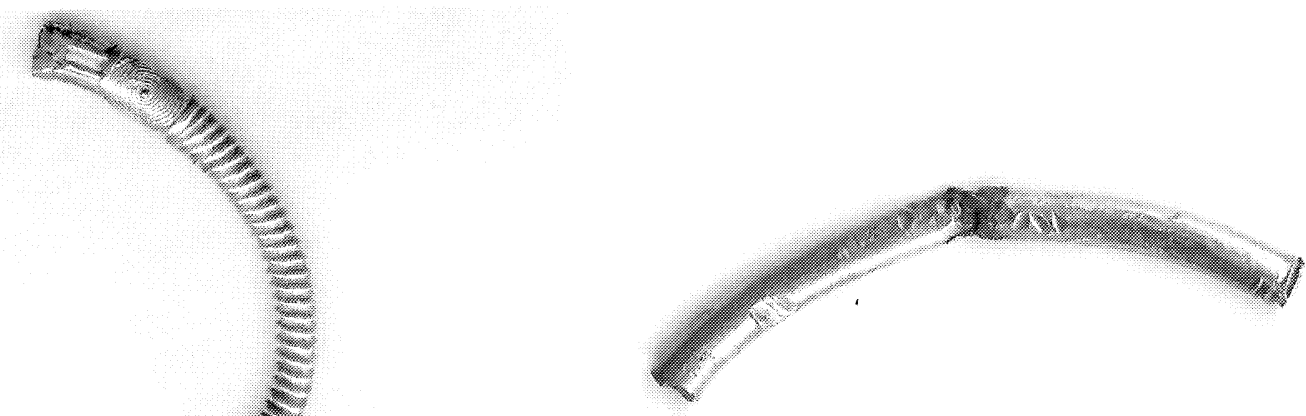

B
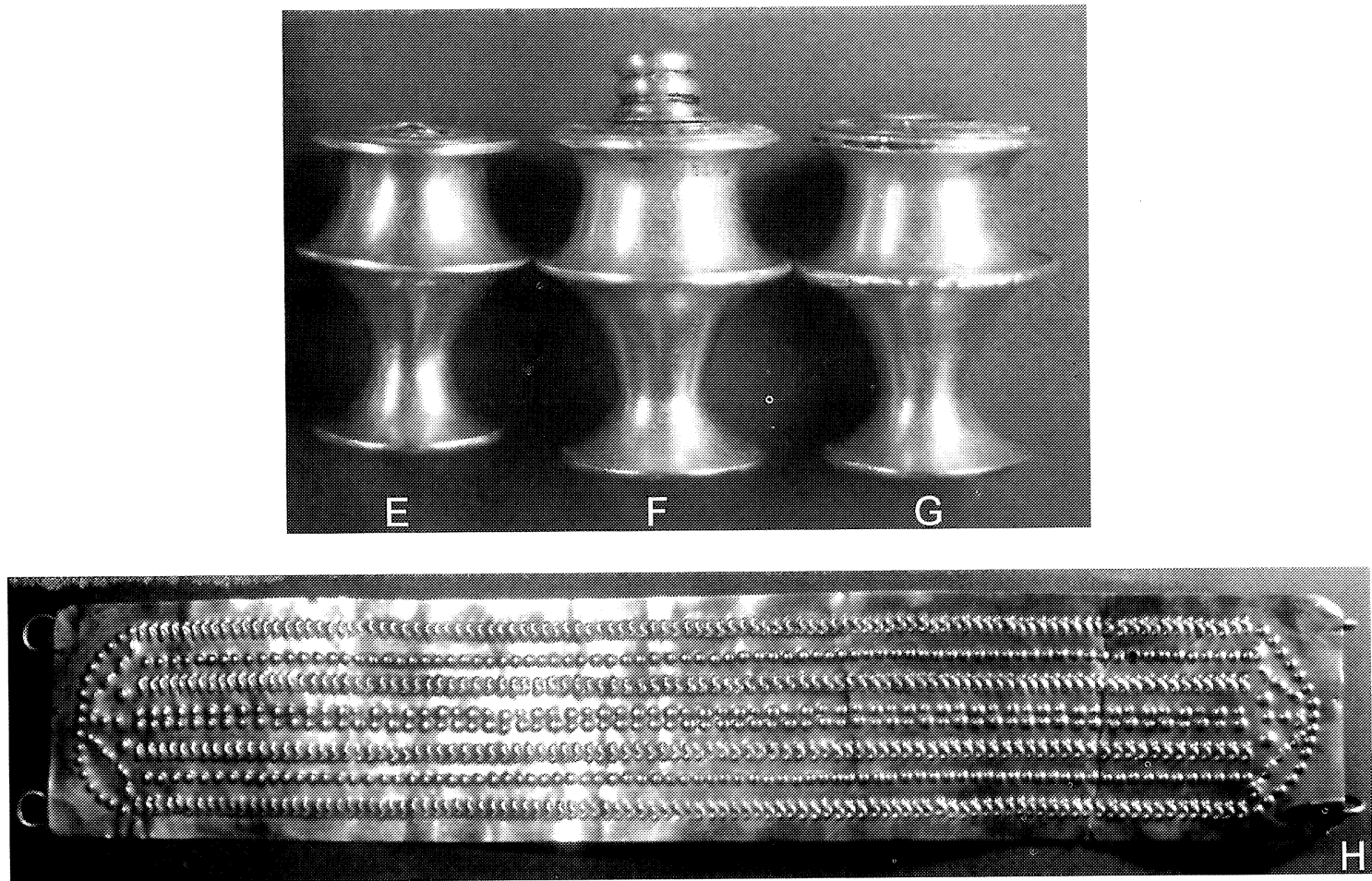

Lám. I. Conjunto de Cangas de Onís: A: torques 33.132; B: varilla 33.133; C: varilla 33.134; D: varilla 33. 135; E: terminal 33.136; F: terminal 33.137; G: terminal 33.138; H: diadema-cinturón 33.139. 


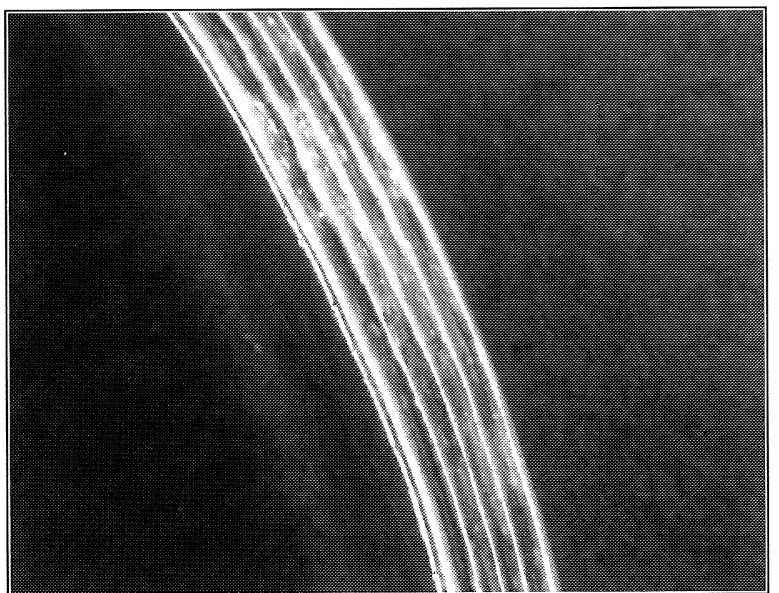

Lám. II. Detalle de la decoración de la varilla del torques 33.132 .

33.137: 0,4 cm; grosor medio de la varilla: $2 \mathrm{~cm}$; diámetro aproximado del orificio de entrada del aro: $1 \mathrm{~cm}$. Peso del n. ${ }^{\circ} 33.137: 73,26 \mathrm{~g}$; peso del n. ${ }^{\circ}$ 33.138: $56,98 \mathrm{~g}$.

c) Fragmento de varilla de torques con sección compuesta. Inventario 33.134 (Lám. I, C): corresponde a un aro cuyo desarrollo se divide en tres tercios, el central presenta sección octogonal y queda delimitado a ambos lados por dos parejas de espirales con botón central, realizadas en filigrana. Los tercios laterales, parcialmente conservados, tienen sección circular y estaban envueltos con alambre enrollado (3). No podemos dar una mayor precisión sobre la morfología y características de los terminales de este torques, aunque apoyamos, con algunas reservas, su pertenencia al fragmento de aro 33.135, descrito a continuación (Álvarez-Ossorio, 1931).

- Dimensiones y peso: longitud: $21,1 \mathrm{~cm}$. Grosor medio: $1 \mathrm{~cm}$; grosor mínimo: $0,55 \mathrm{~cm}$. El grosor medio del hilo de las espirales: $0,15 \mathrm{~cm}$. Grosor estimado de los alambres laterales: $0,25 \mathrm{~cm}$. Peso: $140,68 \mathrm{~g}$.

d) Fragmentos soldados de varilla de torques. Inventario 33.135 (Lám. I, D): dos fragmentos de aro de sección circular. Su superficie presenta numerosos cortes y huellas de extracciones de mate-

(3) Pequeños restos de alambres y marcas de su colocación en la superficie del metal son aún visibles, pese al desgaste y mal estado de conservación de la pieza. La existencia de estos tramos, ignorada en muchos trabajos, ya fue insinuada por algunos autores (López Cuevillas, 1951a: 44; Monteagudo, 1952: 296).

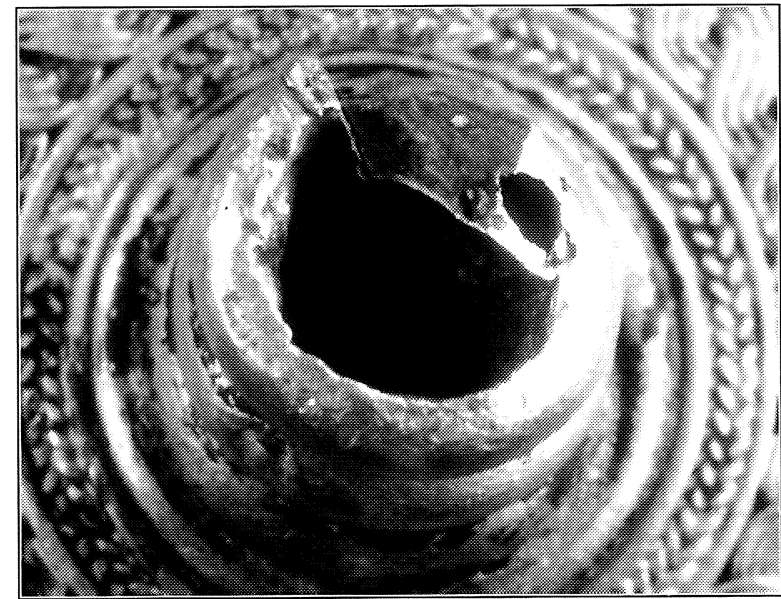

Lám. III. Restos de varilla con alambre enrollado y del alma de plata del aro en la parte posterior del terminal 33.137.

rial, así como restos de diversos procesos técnicos en sus extremos. En su estado original, ambos fragmentos formarían probablemente parte de los tercios laterales del aro 33.134, estando recubiertos de alambre enrollado.

- Dimensiones y peso: longitud de $8,8 \mathrm{~cm}$; grosor medio: $0,6 \mathrm{~cm}$, grosor máximo: $0,8 \mathrm{~cm}$. Peso $33,83 \mathrm{~g}$.

e) Terminal hueco en doble escocia con decoración. Inventario 33.136 (Lám. I, E): con características formales similares a las del terminal completo del torques 33.132, al que también se asemeja en su proceso de elaboración.

- Dimensiones y peso: altura: 4,2 cm. Diámetro de la placa frontal: $2,6 \mathrm{~cm}$; diámetro placa posterior: 2,75; diámetro máximo: $3,15 \mathrm{~cm}$. Pesa $34,81 \mathrm{~g}$.

f) Diadema-Cinturón de lámina rectangular decorada. Inventario n. ${ }^{\circ} 33.139$ (Lám. I, H): presenta los lados cortos ligeramente redondeados y un sistema de sujeción formado por una pareja de anillas y otra de ganchos, soldados al reverso de la lámina. El cuerpo central está decorado por estampado, con series longitudinales de puntos de diferentes tamaños y motivos en S (Lám. IV), que se han interpretado como estilizaciones de ornitomorfos (Blanco, 1957: 137; Pérez Outeiriño, 1980).

Originalmente la pieza se encontró enrollada sobre sí misma, probablemente con rotura parcial en uno de sus lados (López Cuevillas, 1951a: Lám. XXXIII). En la actualidad ha sido reparada mediante dos puntos de soldadura blanda con estaño. 


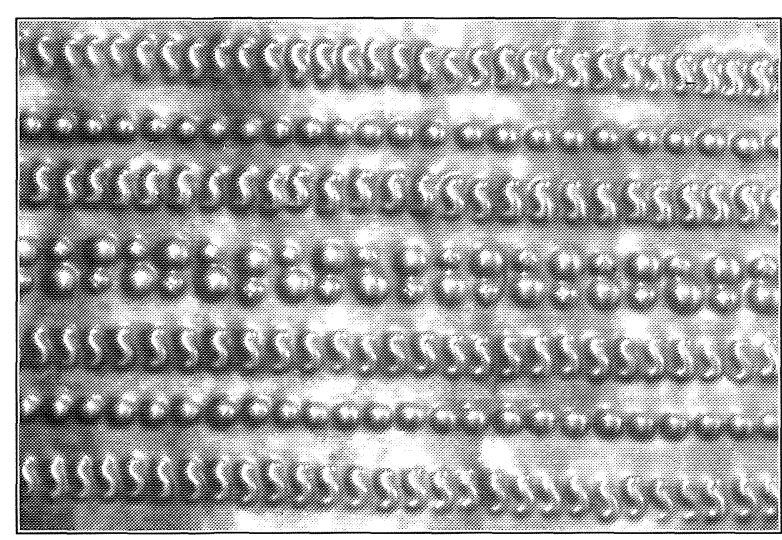

Lám. IV. Secuencia decorativa de la zona central de la diadema 33.139.

- Dimensiones y peso: altura: $7 \mathrm{~cm}$. Longitud: $39,5 \mathrm{~cm}$; grosor del alambre en anillas y ganchos: 0,2 cm. Pesa 76,01 g (Álvarez-Ossorio, 1931, 1954: 4).

\section{LOS GRUPOS MORFOLÓGICOS REPRESENTADOS}

Recientemente se han definido dos grupos básicos para el estudio del trabajo del oro en la región asturiana durante la II Edad del Hierro, que difieren principalmente en sus características morfotécnicas y en el material de fabricación de los objetos. Ambos se caracterizan por una gran variabilidad morfológica y por combinar técnicas de origen mediterráneo, como la soldadura, la filigrana o el granulado, junto a otras de tradición local, como el vaciado a la cera perdida, el vaciado adicional y la estampación (Perea y Sánchez-Palencia, 1996: 42; Armbruster y Perea, 2000).

El grupo Astur-Meseteño emplea mayoritariamente la plata como material de base, aunque también el oro. Este grupo está más relacionado con la orfebrería celtibérica del Duero, sus tipos más representativos son torques, brazaletes y objetos, como fíbulas y arracadas (Perea y Sánchez-Palencia, 1996: 37).

El grupo Norteasturiano se integra plenamente en la orfebrería castreña del Noroeste y emplea preferentemente el oro como materia prima. Sus tipos más representativos son torques, diademas-cinturón y objetos como colgantes-amuleto, placas decoradas, arracadas o hebillas. En este segundo grupo se incluyen las piezas del conjunto de Cangas de Onís (Lám. I).

\section{Torques}

Aunque el estudio de este tipo de pieza es el campo con más aportaciones en la investigación de la orfebrería castreña, ninguna de las sistematizaciones propuestas se adapta a las características morfotecnológicas de todos los ejemplares, en muchos casos por estar éstos insuficientemente estudiados en el momento de elaboración de los catálogos, y en otros, por no tener en cuenta tal o cual aspecto de estudio. En la práctica, no existe una síntesis actualizada para todas las piezas conocidas.

Los torques del grupo Norteasturiano presentan una gran variedad en sus formas de elaboración, fruto de una evolución local y del contacto con otras regiones dentro y fuera del ámbito castreño; las varillas pueden tener sección poligonal, circular o cuadrada-romboidal, con formas macizas, huecas o con alma de otro material y presencia o ausencia de alambres enrollados. Los terminales, en doble escocia, también varían en su diseño y técnicas ornamentales; pueden ser huecos o macizos, incluir diversas técnicas de decoración y presentar o no elementos de sonajero en el interior (Perea y SánchezPalencia, 1996; Armbruster y Perea, 2000).

Como característica habitual, destaca el empleo de la técnica de la cera perdida; este procedimiento sirvió para elaborar formas complejas que sustituyen en ocasiones a los trabajos de filigrana o granulado, técnicas también presentes en este grupo y observables en ejemplares de otras regiones, como el terminal del castro de Santa Tecla, en Galicia o el torques de Vilas Boas, en el Norte de Portugal (Armbruster y Perea, 2000: 106).

Junto a este procedimiento, el estampado se utilizó frecuentemente como parte de la decoración de los terminales y varilla, siendo también la técnica ornamental básica de las diademas cinturón castreñas, piezas que en su mayoría se concentran en el área asturiana.

A lo largo del tiempo, se han sucedido varios intentos de clasificación, que han tenido en cuenta características como el perfil de los terminales o la morfología de las varillas, añadiendo la presencia y disposición de elementos ornamentales como factores de variabilidad dentro de los distintos grupos establecidos. En menor medida, estos trabajos han hecho referencia a las técnicas de fabricación de los objetos para establecer las tipologías; tras los trabajos pioneros de Villaamil y Castro, el primer intento de sistematización tipológica para los torques castreños fue el de López Cuevillas en 1932. 
Este autor realiza una nueva catalogación en 1951, fundamental para los estudios posteriores en la materia.

Cuevillas clasificó los torques en varias escuelas. Según su propuesta, la mayor parte de las piezas del conjunto de Cangas de Onís pertenecerían a la escuela Asturiana, caracterizada por terminales asimétricos en doble escocia, alambre enrollado, espirales de filigrana y molduras longitudinales en la parte central del aro, piezas como el torques de Langreo o el ejemplar 33.133-37-38 de nuestro conjunto serían un buen ejemplo de esta escuela (López Cuevillas, 1951a: 50).

Entre los torques con remates en doble escocia, López Cuevillas diferencia un taller Flaviense, esbozado anteriormente por M. Cardozo (1942: 98) y definido por torques con aros de sección romboidal, donde quedaría integrado el torques 33. 132 (Lám. I, A), o piezas como el Torques de Paradela I.

En 1952, una nueva clasificación de L. Monteagudo, más flexible en cuanto a la morfología de los terminales, permitiría incluir el torques al que pertenen los fragmentos 33.133 y los terminales 33.137 y 33.138, así como el fragmento de torques 33.134 , en el tipoastur-norgalaico (Lám. I, B, F, G, C), junto a ejemplares como los torques de Langreo, Coaña o Cu do Castro (Monteagudo, 1952: 294 y ss). En 1965 Bouza Brey añadirá a esta clasificación el tipo Nororiental-galaico (Bouza, 1965: 10).

Los intentos posteriores han tomado como referencia básica estas tipologías, con diferentes matizaciones (Raddatz, 1969, Pérez-Outeiriño, 1990; Balseiro, 1994; Prieto, 1996). Estos trabajos ponen de manifiesto la necesidad de realizar una catalogación previa de la información documental, analítica y técnica de estos ejemplares como único modo de afrontar su completa sistematización (Pérez Outeiriño, 1990: 140).

Así, las últimas aportaciones trascienden la sistematización tipológica y abarcan aspectos como la interpretación simbólica y económica de las piezas (Prieto, 1996; Castro, 1998; Ladra, 1999), la sistematización regional o el estudio de materiales inéditos (Balseiro, 1994; Ladra, 1997-98).

Algunos trabajos, finalmente, plantean una aproximación general a la tecnología de estas sociedades o plantean de forma abierta la no validez de la tipología como argumento definitivo para el conocimiento de estas piezas, proponiendo el estudio tecnológico como argumento fundamental en su investigación (Perea y Sánchez-Palencia, 1996; Armbruster y Perea, 2000).

\section{Diademas-Cinturón}

Son piezas de estructura laminar decorada, con un sistema de cierre o sujeción formado por anillas o ganchos. Pueden o no incluir elementos ornamentales plásticos añadidos. Este grupo, con un ejemplar representado en el conjunto de Cangas de Onís, muestra aún numerosos problemas de definición; su propio nombre refleja, más que un determinado nivel de conocimiento, la falta de consenso sobre la funcionalidad o modo de uso de estas producciones, debate que podemos extender a la estimación de su cronología o procedencia, pues las circunstancias de recuperación y los avatares posteriores de la mayor parte de los ejemplares nos son prácticamente desconocidos.

Conocemos un total de siete ejemplares: dos en el conjunto de Moñes, conservados en el M.A.N, Instituto CondeValencia de Don Juan y Musée des Antiquités Nationales (García Vuelta y Perea, e.p.; Balseiro, 2000; Perea y Sánchez-Palencia, 1996; Marco, 1994, entre otros); otros dos procedentes del área Vegadeo-Ribadeo, conservados en el M.A.N. y el Museo Lázaro Galdiano (López-Cuevillas, 1951 a y b) (4); uno en el castro de Elviña, conservado en el Museo del Castillo de San Antón de A Coruña (Luengo, 1979; Reboredo, 1996); uno en el conjunto Bedoya, en el Museo de Pontevedra (Balseiro, 1997) y por último el perteneciente al lote de Cangas de Onís.

La cronología y pervivencia de estos ejemplares son aspectos controvertidos, aunque las piezas de estructura laminar cuentan con una larga tradición en el Noroeste Peninsular, es difícil establecer un nexo cronológico entre estas piezas y las producciones anteriores. Sólo para el ejemplar de Elviña, excavado en la década de los 50, contamos con un contexto arqueológico conocido, con un momento de ocultación datado en el siglo I d.C., igual que el de la didadema-cinturón del tesoro Bedoya. El resto carece de procedencia fiable y se concentra en su mayor parte en territorio asturiano y en el límite entre Asturias y Galicia.

$\mathrm{Al}$ igual que los torques, las «diademas-cinturón» presentan notables diferencias formales en la disposición y morfología de sus elementos estructurales, que dificultan un intento de clasificación tipológica. A grandes rasgos, podemos diferenciar tres: láminas de base, sistemas de cierre o sujeción

(4) Según este autor, existiría un tercer ejemplar en el Museo del Louvre, del que hasta la fecha no se ha podido recuperar ninguna información.

T. P., 58, n. ${ }^{\circ} 2,2001$ 
y elementos plásticos añadidos, este último con un carácter estructural u ornamental.

Con la excepción del ejemplar del tesoro Bedoya, de forma elíptica, se realizaron a partir de una o varias láminas rectangulares decoradas por estampación, con sistemas de sujeción o cierre formados por la soldadura a las láminas centrales de anillas o ganchos en sus lados cortos. Pueden presentar, como en los ejemplares de Moñes o Elviña, elementos plásticos añadidos.

Respecto a su funcionalidad, la hipótesis más aceptada es la de adornos de cabeza o diademas. Aunque esa utilidad resulte probable, el análisis detenido de las dimensiones y características físicas de las piezas podría invalidar esta teoría. En cualquier caso, la fragilidad de las láminas de base hace difícil su utilización sin un soporte flexible, probablemente realizado en cuero o tela, que ampliaría sus posibilidades de utilización. Desconociendo la morfología de estos soportes, creemos más prudente una definición mixta, como la que se recoge, para este grupo (Perea y Sánchez-Palencia, 1996; García Vuelta y Perea, e.p.).

\section{AVATARES Y NATURALEZA DEL CONJUNTO}

Desconocemos el contexto, el lugar y la fecha del hallazgo, que en cualquier caso fue anterior a 1902-1903, momento en el que parte de estas piezas figuran entre las láminas de la obra "Recuerdos de Asturias" de D. Eduardo Llanos, como pertenecientes a la colección Soto Cortés (Somoano, 1960a: 273). Esta colección, para la que se realizaron durante un largo período de tiempo numerosas adquisiciones en diversos puntos de Asturias y Galicia, fue fundada por D. Felipe de Soto Posada, siendo ampliada posteriormente por D. Sebastián de Soto Cortés, primer propietario conocido de las piezas tras su descubrimiento.

Apenas tenemos noticias del momento o momentos de la compra de estos materiales, por lo que no podemos definir con certeza si su localización geográfica se asignó inicialmente por la ubicación de la colección Soto Cortés o por la existencia de esta referencia en alguna documentación de la adquisición, que hasta hoy permanecería inédita. Los documentos que hemos podido consultar no apuntan ningún dato a este respecto.

Tras la muerte de Sebastián de Soto Cortés, ocurrida en 1915, la colección se dispersa parcialmente
(Somoano, 1960 a: 272). A finales de los años $20 \mathrm{e}$ inicios de los 30 , diversas piezas de oro castreño procedentes de ésta, fueron ofertadas a varios museos e instituciones.

De esta manera, el Instituto Conde Valencia de Don Juan adquirió al platero ovetense Pedro Álvarez, en 1928, un torques de oro con supuesta procedencia de Langreo (Asturias). En 1931 esta misma institución compra al marqués de Valverde de la Sierra, entre otros materiales, una hebilla anular de oro y uno de los fragmentos de las diademas-cinturón del conjunto de Moñes (Maya, 1987-88: 127 y ss ; García Vuelta y Perea, e.p.).

A finales de 1930, el M.A.N. recibe el ofrecimiento de venta de los siete fragmentos de torques y la diadema-cinturón que integran el lote de Cangas de Onís. Actuó como vendedor D. Manuel Ruiz Balaguer (5) y fue D. Francisco Álvarez-Ossorio, el encargado de su evaluación y de tasar el lote. Tras dos informes favorables a la adquisición de las piezas los días 12 y 16 de diciembre de ese año, el conjunto es adquirido por el estado el 20 de enero de 1931 por 19000 pesetas. En la actualidad, forma parte de las colecciones del Dpto. de Protohistoria y Colonizaciones del M.A.N.

\section{Naturaleza del hallazgo}

Desde el primer estudio de las piezas, publicado el mismo año de su adquisición (ÁlvarezOssorio, 1931), los investigadores aceptaron con reservas su supuesta procedencia. A partir de estos momentos y de la mano de diversas revisiones de conjunto, el debate sobre las piezas de Cangas se ha centrado principalmente en sucaracterización tipológica (López Cuevillas, 1951a; Monteagudo, 1952; Álvarez-Ossorio, 1954, etc.).

Sin embargo, en 1960, Celso Diego Somoano plantea un nuevo interrogante, dudando de la composición original del conjunto a partir de la presencia de parte de sus piezas en la mencionada obra de Eduardo Llanos, donde no figuran la diadema-cinturón 33.139, ni los terminales de torques 33.137 y 33.138. Según esto, Somoano apunta que estas piezas pudieron pertenecer a varios hallazgos diferentes, opinión que recogerán posteriormente otros autores (Maya, 1987-1988: 138).

(5) El primero de los expedientes de compra de estas piezas figura en el archivo del Museo Arqueológico Nacional con el número 1930/11. El expediente definitivo de la adquisición se archiva con el número $1931 / 11$ 
Pensamos que estos argumentos deben ser tenidos en cuenta, aunque hay que considerar que no sólo desconocemos las circunstancias de la recuperación de las piezas, sino también en qué momento los materiales fueron vendidos a la colección o si esta adquisición se realizó en una o en varias operaciones distantes en el tiempo, posibilidad que bien pudo ocasionar la ausencia de parte de los materiales en la publicación de Llanos.

Aunque las características técnicas de los aros y terminales de torques del lote presentan clara relación en cuanto a sus técnicas y morfología, opinión que hemos defendido en otros trabajos (García Vuelta, e.p.). Nuevas informaciones procedentes de la correspondencia mantenida entre D. Sebastián de Soto Cortés y D. J.R. Mélida en abril de 1906 apuntan nuevas dudas.

A petición de J.R. Mélida, Sebastián de Soto Cortés informó a éste en varias cartas sobre algunos objetos de su colección. En el borrador de una de ellas, conservado por $\mathrm{D}^{\mathrm{a}} \mathrm{M}^{\mathrm{a}}$ Teresa Pendás y único documento que tenemos de esta correspondencia, se describe uno de los torques del lote (33.13337 y 38), precisando que la pieza habría sido adquirida pocos años antes, rota en 4 partes e incompleta, junto a otros dos fragmentos de torques. En el documento no se alude a ninguna otra de las piezas que actualmente integran este lote (6).

Estos datos, que contrastan con la tesis de Somoano y añaden nuevas dificultades al estudio documental de las piezas, parecen indicar que la adquisición inicial constaba tan solo de un torques fragmentado, que no quedó incluido en su totalidad en las láminas citadas por este autor y de dos fragmentos más, pertenecientes a uno o varios torques, que bien pudieron pertenecer al mismo hallazgo o a otro distinto. No podemos determinar la morfología de dichos fragmentos, que pueden pertenecer a otras piezas del lote, probablemente a los restos de aro 33.134 y $33.135(7)$.

Tampoco se alude a la diadema-cinturón 33.139 ni al resto de las piezas que actualmente integran el conjunto, aunque Soto Cortés hace mención a un broche que no pudo adquirir y que bien pudo formar parte del mismo hallazgo. Según esto el resto de las

(6) El estudio completo de esta interesante información sobre éste y otros hallazgos, aún en fase de elaboración, verá la luz en próximos trabajos.

(7) Pensamos que las características y decoración del terminal 33.136 o la del torques incompleto 33.132 hubiesen recibido una mención específica de Soto Cortés en su descripción de la adquisición. piezas que componen el conjunto actual, sin que podamos precisar definitivamente su pertenencia o no a un mismo hallazgo original, se habrían añadido al mismo entre 1906 y 1915, fecha de la muerte de Sebastián de Soto Cortés. La aparición de nuevos datos sobre la colección, cuya documentación se haya dispersa, apuntará sin duda nuevas e interesantes informaciones al respecto.

\section{Cronología de las piezas}

Los diferentes estudios asignan para los torques de este grupo unas fechas que varían entre los siglos III al I a.C. En esta línea apuntan también los últimos trabajos, que sitúan el conjunto en una fecha próxima al cambio de era, momento con el que estamos más de acuerdo. Pensamos que las similitudes técnicas y morfológicas de las piezas, que se analizan en el siguiente capítulo y que parecen apuntar a un mismo taller de fabricación, señalan la unidad temporal de estos materiales, independientemente de su posible asociación deposicional.

La datación de la diadema-cinturón presenta más problemas, ya que las cronologías propuestas para los ejemplares varían entre los siglos V-IV a.C. al I d.C, discutiéndose la pervivencia de este tipo de piezas. Las dificultades expuestas para la asociación de esta pieza con el resto de los materiales del conjunto no permiten el planteamiento de nuevos datos a este respecto.

\section{ANÁLISIS TÉCNICO Y TECNOLÓGICO}

El estudio de estos materiales se ha realizado según los diferentes grupos morfológicos (torques y diademas-cinturón) y los elementos estructurales que integran cada pieza. En el caso de los torques hemos individualizado tres elementos básicos: aros o varillas, terminales y elementos ornamentales plásticos añadidos, que en algún caso cumplen también una función estructural $\left(\mathrm{n}^{\circ}{ }^{\circ}\right.$ 33.133). En la diadema-cinturón diferenciamos dos: lámina de base con decoración y sistema de cierre o sujeción.

Metodológicamente hemos empleado la microscopía óptica para documentar las alteraciones y procesos de desgaste del metal, así como las huellas de procesos técnicos y herramientas de fabricación. Los resultados del estudio topográfico, que en el futuro deben completarse con una nueva interpre-

T. P., 58, n. ${ }^{\circ} 2,2001$ 
tación analítica de las piezas (8) se han documentado con fotografía macro aunque hemos empleado también imágenes micrográficas generadas desde el Proyecto AU (9).

\section{Grupo 1. Torques}

a) Aros o Varillas: conservamos un aro completo con un remate y restos de otro (33.132) y 4 fragmentos de aro, dos de ellos unidos por soldadura (33.135). Estas piezas pertenecen a 3 torques diferentes, $(33.132,33.133$ y 33.134-35), que difieren notablemente en sus técnicas de fabricación, morfología y ornamentación. Sólo en dos ejemplares (33.132 y 33.133) podemos realizar una asociación entre aros y terminales.

Varilla del torques 33.132: tiene sección maciza y se retocó mediante martillado, proceso que dejó huellas visibles en la parte central y extremos del aro. Las zonas decoradas con estrías se realizaron con un punzón simple que dejó claras huellas en varios puntos del interior de las mismas, a pesar del pulido posterior que sufrió el torques y de la rubefacción que altera parte de su superficie (ver Lám. II). El uso de la pieza se confirma por las huellas de desgaste que presenta en sus caras internas, especialmente en su parte central.

Fragmento de Aro 33.134: esta varilla fue trabajada por martillado para lograr la forma ochavada de su zona central (Lám. V, 1) que presenta los laterales ligeramente cóncavos, con huellas de desgaste por uso en la zona interna. Esta sección se repasó con un pulido de acabado, mucho menos marcado en el tramo lateral conservado, de sección circular adelgazada hacia los extremos.

Los tramos laterales se retocaron con martillado antes de disponer el alambre enrollado que los envolvió. La presencia de alambres se confirma por las ligeras huellas que dejaron sobre la superficie del metal (Lám.V, 2), visibles aún en varias zonas del aro y por algunos restos observables cerca de la zona de espirales de filigrana con botón central

(8) Los resultados de los estudios analíticos previos (Hartmann, 1982), se emplean en la argumentación, aunque no se consideran como definitivos al desconocer algunos aspectos básicos, como la zona de obtención de las muestras, aspecto decisivo para la interpretación de estos materiales.

(9) Dirigido por la Dra. Alicia Perea desde el Dpto. de Prehistoria, Instituto de Historia, CSIC.

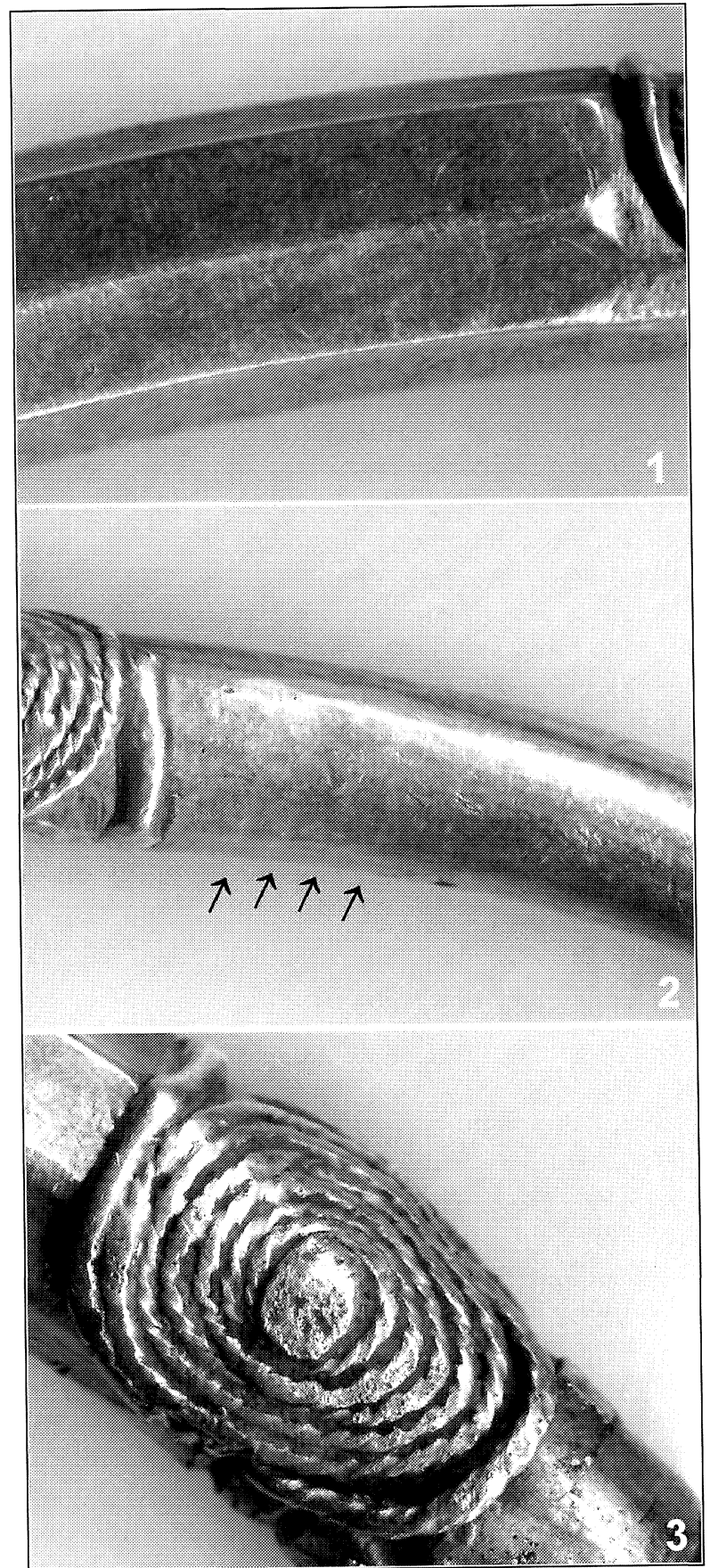

Lám. V. Varilla 33.134; 1 . Detalle del trabajo de la zona central del aro; 2 . Restos y huellas de las espiras de alambre enrollado en los tercios laterales del aro; 3 . Detalle de la filigrana en las espirales y restos de alambre enrollado (zona inferior izquierda).

(Lám.V, 3). Su grosor aproximado era de $0,25 \mathrm{~cm}$ y presentaban sección plano-convexa.

No disponemos de más datos para realizar la 
reconstrucción completa de este torques, desconociéndose la morfología de sus terminales, que probablemente presentarían una tipología en doble escocia, al igual que el resto de los conservados.

Posiblemente, el fragmento descrito pertenece al mismo torques que el n. ${ }^{\circ} 33.135$, sin embargo, las diferencias en su composición analítica nos hacen dudar, dadas las diferencias de casi un 10\% de $\mathrm{Ag}$ en la aleación (Hartmann, 1982). En cualquier caso, y desconociendo las zonas exactas donde se obtuvieron estas muestras, no podemos emplear este dato como un argumento definitivo.

Cada una de las dos espirales dobles que delimitan las secciones del aro se realizaron a partir de un hilo de sección plano convexa, aplanado mediante martillado o batido. El grosor medio de este hilo es de $0,15-0,2 \mathrm{~cm}$. A estas espirales, con una media de 10 espiras de hilo cada una, se le añadieron sendos glóbulos centrales, fijados por soldadura, proceso que fundió parte de sus hilos (Lám.V, 3).

La pieza presenta huellas de numerosos cortes antiguos y extracciones de metal a lo largo de toda la varilla, es probable que la extracción del alambre enrollado del lateral conservado se produjese en un momento previo a la deposición u ocultación de la pieza.

Fragmentos de aro 33.135: su interés radica principalmente en las manipulaciones que sufrieron tras seccionar la pieza a la que pertenecieron, probablemente, el mismo torques del que formó parte el fragmento 33.134.

Su superficie fue retocada mediante martillado y presenta numerosas huellas de cortes y extracciones de metal con factura antigua. Una observación detenida confirma que parte de las marcas no corresponden a simples cortes; en uno de sus extremos, en una estrecha franja de unos $0.5 \mathrm{~cm}$ de desarrollo, el metal fue parcialmente cortado y sometido a un proceso de estampado con un punzón simple de punta rectangular, cerca del lugar donde previamente se habían efectuado extracciones de metal de disposición lineal. Esta parte de la pieza fue, además, rematada por martillado, eliminando las huellas de su seccionamiento y dejando una superficie redondeada (Lám. VI, 1).

Estas evidencias pueden apuntar a una utilización de los fragmentos como soporte de pruebas de orfebre en época antigua, aunque parte de éstas, como algunas extracciones de metal o la soldadura visible en la zona central, presentan una interpretación arriesgada. La unión de los dos fragmentos

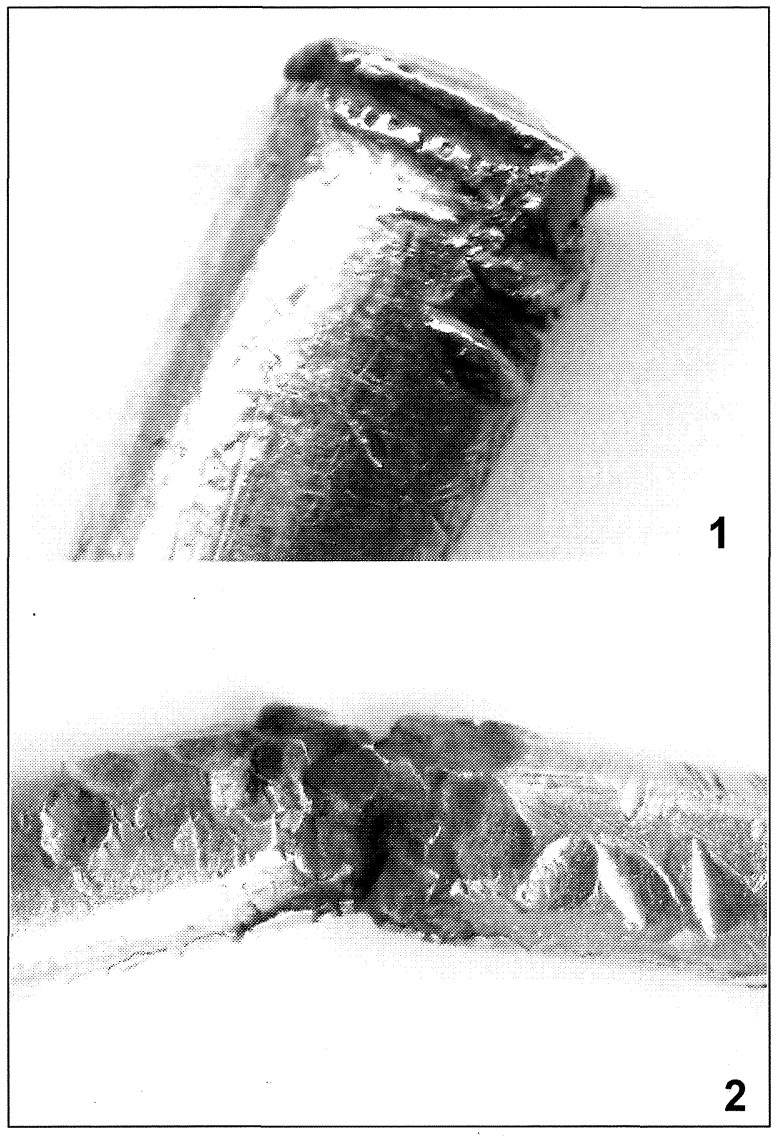

Lám. VI. Varilla 33.135: 1. Huellas de la aplicación de pruebas técnicas en uno de los extremos del fragmento; 2 . Detalle de la soldadura de la zona central.

se realizó mediante soldadura, añadiendo como material soldante pequeñas láminas de oro con una aleación de alto contenido en plata (Lám.VI, 2).

Aunque el empleo de este sistema se observa en piezas castreñas como las diademas-cinturón del conjunto de Moñes (García Vuelta y Perea, e.p.) y las características de los fragmentos podrían hacer verosímil la hipótesis de la realización de una prueba técnica sobre el mismo, pensamos que el estudio topográfico no es definitivo para determinar la naturaleza de esta soldadura. Quedamos pues a la espera de un estudio analítico que permita aportar nuevos datos al respecto.

Fragmento de aro del torques 33. 133: este torques, originalmente incompleto y del que se recuperaron 4 fragmentos, faltando actualmente un tramo lateral con 14 espiras de hilo, según la referida documentación de Sebastián Soto Cortés, presenta unas características formales muy semejantes a 
las del ejemplar de Langreo conservado en el Instituto Valencia de Don Juan (Maya, 1987-88: 140); probablemente ambos pertenecieron a un mismo taller de fabricación.

La varilla de esta pieza fue cortada con una herramienta de tipo zizalla, que produjo una notable deformación por aplastamiento, así como diversas grietas en su superficie; esta rotura, sin embargo, nos permite reproducir su proceso de fabricación.

El aro 33.133 se construyó mediante la superposición de diversos elementos de oro independientes sobre una barra de plata, posiblemente aleada con plomo, de sección rectangular adelgazada del centro a los extremos mediante martillado (Lám. VII, 1).

El primero de estos elementos, una placa cilíndrica con decoración geométrica, probablemente hueca, se elaboró a la cera perdida y se colocó sobre la parte central del aro de plata. Esta placa se realizó a partir del vaciado de un modelo previo, donde se dispusieron las series decorativas mediante estampado e incisión (Lám. VII, 2).

La decoración afecta a dos tercios de la sección del cuerpo, dejando una parte exenta. Los motivos se disponen en 5 bandas de 2,5 $\mathrm{mm}$ de anchura y alternan series de finas líneas paralelas con otras de triángulos enfrentados con motivos circulares en su interior. Cada una de estas bandas queda separada por un junquillo en resalte de sección cuadrangular y $1,5 \mathrm{~mm}$ de anchura.

Una vez fundida, la placa se dispone sobre el aro de plata, con la zona sin decorar hacia el interior, para facilitar el uso de la pieza. A continuación, cada uno de los tercios laterales del aro se recubrió, desde la placa central a los terminales, con alambre enrollado de sección cóncavo convexa, realizado a partir del martillado de una tira laminar de oro sobre un yunque de estrías de esa misma sección, como indican las rebabas observables en sus bordes. Tan solo conservamos parte de uno de estos tramos, de 33 espiras, con un grosor medio de $0,4 \mathrm{~cm}$ (Lám. VIII,1 y 2), faltando en la actualidad otro tramo de 14 espiras. Otro fragmento de aro se conserva en el terminal 33.137.

Chapada así la superficie del aro, la zona de contacto entre la sección central y cada uno de los tramos laterales se disimuló con una placa soldada de $2,5 \mathrm{~cm}$ de anchura de forma ovalada que representa un motivo de doble espiral con botón central, fabricada a la cera perdida. Los motivos representados imitan hilos de filigrana sobre fondo granulado (Lám. VII, 3).

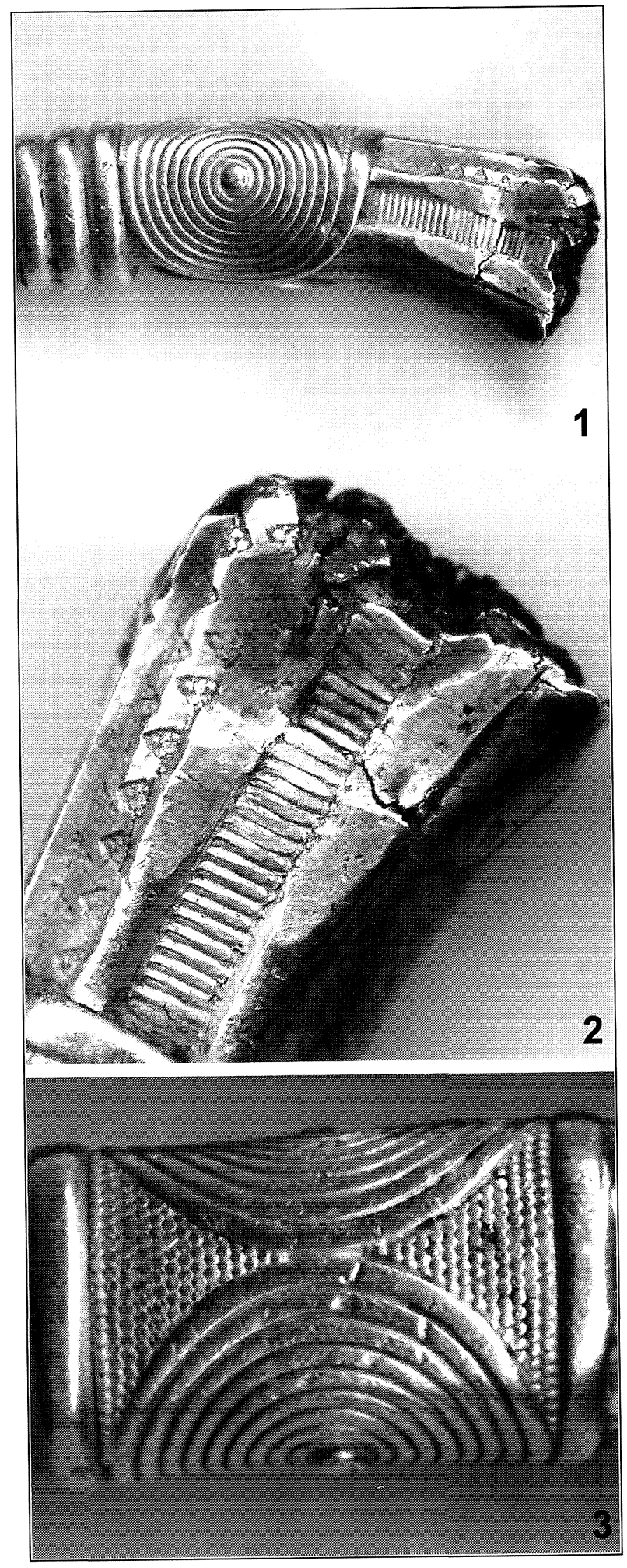

Lám.VII. Varilla 33.133. Detalles de los elementos añadidos al aro: 1. Cuerpo central, detalle. 2. Bandas decoradas; 3. Zona central de la placa con espirales. 


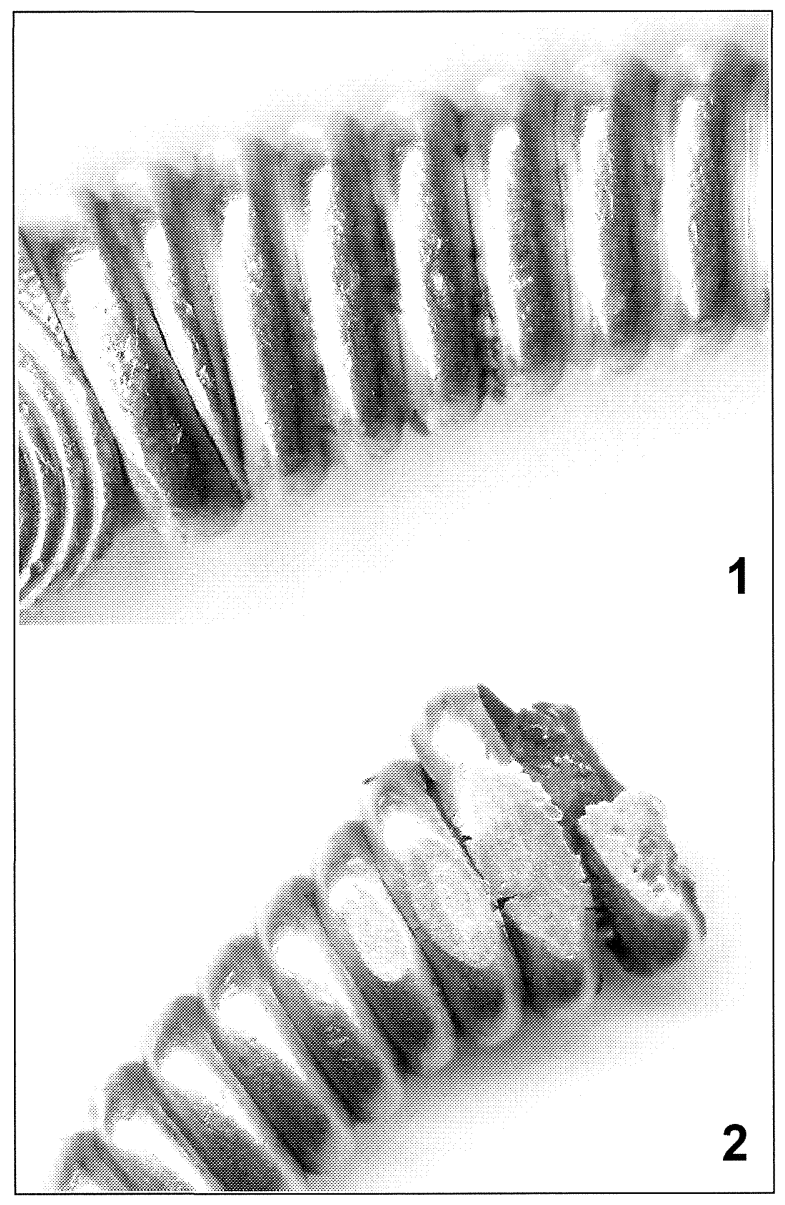

Lám. VIII. Varilla 33.133. 1 y 2. Detalle de la morfología de los alambres enrollados en los tercios laterales del aro.

b) Terminales: conservamos un total de cuatro, todos ellos son objetos con simetría de revolución, construidos a partir de la unión de cuatro elementos independientes: una placa circular frontal, una placa circular posterior y dos cuerpos centrales. Todos son huecos y presentan perfil en doble escocia, aunque difieren ligeramente en el proceso de fabricación de sus placas frontales y posteriores, así como en la elaboración de sus elementos ornamentales. Uno de ellos, correspondiente a la pieza 33.132 , presenta un cuerpo interior a modo de sonajero, característica observable también en otros torques castreños (Armbruster y Perea, 2000).

Los cuerpos centrales de los terminales se moldearon previamente en material blando, utilizando para ello una herramienta rotativa, probablemente un torno de eje horizontal. Una vez obtenidas por este procedimiento las formas básicas de los cuer-

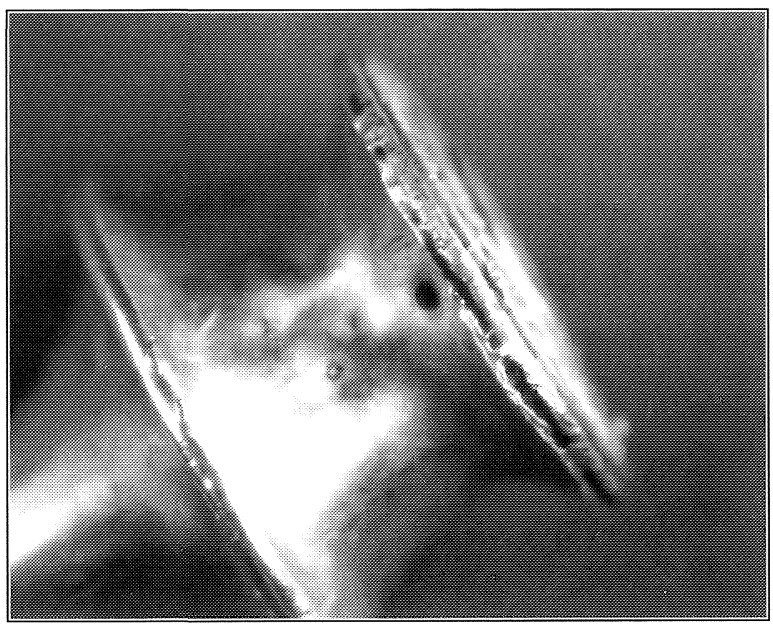

Lám. IX. Terminal 33. 138. Orificio de expansión de gases y restos de la soldadura de la placa posterior del terminal a los cuerpos centrales.

pos, éstas son fundidas y posteriormente soldadas entre sí. El mismo procedimiento se empleó para unir las placas frontales y posteriores a esta estructura, que en los ejemplares 33.137 y 33.138 se fabricaron también a la cera perdida (Armbruster y Perea, 2000: 102).

Conformadas así estas piezas, su superficie sufre un pulido de acabado, más acusado en la zona de contacto entre los elementos, para eliminar las huellas de las soldaduras, que observamos en todos los terminales tras la destrucción de los torques (Lám. IX).

Una característica común a los terminales de este conjunto es la presencia de un pequeño orificio circular situado en su cuerpo central posterior. Estas perforaciones fueron realizadas con un punzón o una torneta con punta afilada de sección circular, cuyas huellas han quedado muy suavizadas por el pulido de las piezas. En los terminales 33.132 y 33.136, la huella presenta una entrada horizontal y se sitúa en la zona más plana del cuerpo central posterior. En los remates 33.137 y 33.138 , el punzón penetró en sentido diagonal, situándose la oquedad más cerca de la parte posterior del terminal, siendo menos visible (Lám. IX).

La interpretación de estos orificios plantea dos posibilidades: la primera es que actuaran como respiraderos para la evacuación de los gases producidos durante el calentamiento de la pieza, con el fin de impedir el colapso de sus caras frontal y posterior; así se han interpretado las perforaciones presentes en terminales como los del torques de Burela 
(Armbruster y Perea, 2000: 104). Una segunda opción es que sean un resto visible del proceso de fabricación a la cera perdida de los cuerpos centrales de los terminales, aunque consideramos esto menos probable (10).

A partir de las diferencias y similitudes expuestas en los terminales del lote, podemos distinguir un primer grupo formado por el n..$^{\circ} 33.136$ y los pertenecientes al torques 33.132 (Lám. X) y otro constituido por la pareja de remates 33.137 y 33. 138, asociados al aro 33. 133 (Lám. XI).

Grupo 1. Terminales 33.132 y 33.136: caracterizado por el recorte sobre chapa de sus placas frontal y posterior y el uso de la estampación como técnica decorativa en las placas frontales, que se rematan con un glóbulo central esférico unido por soldadura.

Los orificios para la entrada del aro fueron recortados directamente sobre la lámina de las placas posteriores, previamente a su unión con el cuerpo del terminal, como podemos observar en el $n^{\circ}{ }^{\circ}$ 33.136. Estas placas no presentan decoración estampada, aunque se fijó en ellas un alambre de sección plano convexa maciza abierta en disposición circular, que sirvió probablemente para la ornamentación de las piezas, actuando a la vez como refuerzo de la estructura de los terminales (Lám. X, 3).

El estudio de los motivos ornamentales permite distinguir el uso de varios punzones complejos, aunque el estado de conservación de las piezas hace difícil determinar la morfología exacta de estas matrices.

En el terminal 33.136 la decoración de la placa frontal se inicia con dos series concéntricas de puntos que enmarcan cuatro figuras diseñadas a partir de líneas onduladas que se completan con circulos concéntricos, alrededor del botón central del terminal (Lám. X, 1). Para la realización de esta decoración, se emplearon dos punzones distintos, quizá tres. El primero, con forma de arco, incluye tres o más motivos esféricos cóncavos y sirvió para estampar las series de puntos que rodean las figuras centrales, así como algunas formas de éstas, donde quizá se empleó otro punzón de parecidas características. El segundo punzón que hemos podido determinar se empleó para rematar las figuras de la parte central del terminal y presenta forma circular, con un motivo concéntrico cóncavo en su interior (Lám. X, 2).

(10) Agradecemos las observaciones de la Dra. Alicia Perea a este respecto.
En el terminal completo de la pieza 33.132 los motivos decorativos se disponen en bandas concéntricas; en la parte exterior observamos dos series de puntos que imitan un doble cordelado, sigue una serie de triángulos con el vértice al interior y motivos circulares inscritos en una posible imitación de granulado (Lám. X, 4). Los mismos motivos, en menor número, fueron repetidos en la zona central del terminal. Esta decoración se realizó con dos punzones complejos: el primero incluye al menos tres motivos esféricos cóncavos dispuestos en forma de arco. Esta herramienta, similar a la observable en el terminal 33.136, se empleó para ejecutar las series de punteado en bandas. El segundo tiene forma triangular, con varios motivos esféricos cóncavos en su interior. Se empleó para realizar las series de triángulos con imitación de granulado (Lám. X, 4).

El terminal fragmentado permite observar las huellas de la soldadura de la placa posterior y el orificio de entrada de la varilla (Lám. X, 6).

Grupo 2. Terminales 33.137 y 33.138: difieren de los anteriores en su tamaño y en el proceso de elaboración de sus elementos ornamentales; las placas frontales y posteriores fueron realizadas a la cera perdida, imitando una doble placa. A diferencia del grupo anterior, el orificio para la fijación del aro se moldeó junto a la decoración de las placas posteriores.

En el terminal 33.138 podemos observar la presencia de restos de plata procedentes del alma de la varilla del torques (Lám. XI, 3), uno de los tramos laterales se conserva parcialmente en el terminal 33.137 (Lám. III).

Las huellas del proceso de fundición de las placas decoradas pueden observarse en varios puntos de la placa posterior de ambos terminales (Lám. $\mathrm{XI}, 4)$.Así mismo, restos de su soldadura a los cuerpos centrales son visibles en el terminal 33.138 (Lám. IX).

Las placas frontales están decoradas con series concéntricas geométricas que se inician al exterior con un motivo de cordelado enmarcado por dos bandas en resalte, al que sigue una serie de róleos imitando granulado (11), dispuesta alrededor de dos bandas paralelas circulares que envuelven una espiral que parte del botón central en re-

(11) Este tipo de decoración puede observarse también en torques portugueses como el de Vilas Boas, donde sí se trata de granulado, o en uno de los ejemplares de Chaves (Perea y Armbruster, 2000). 

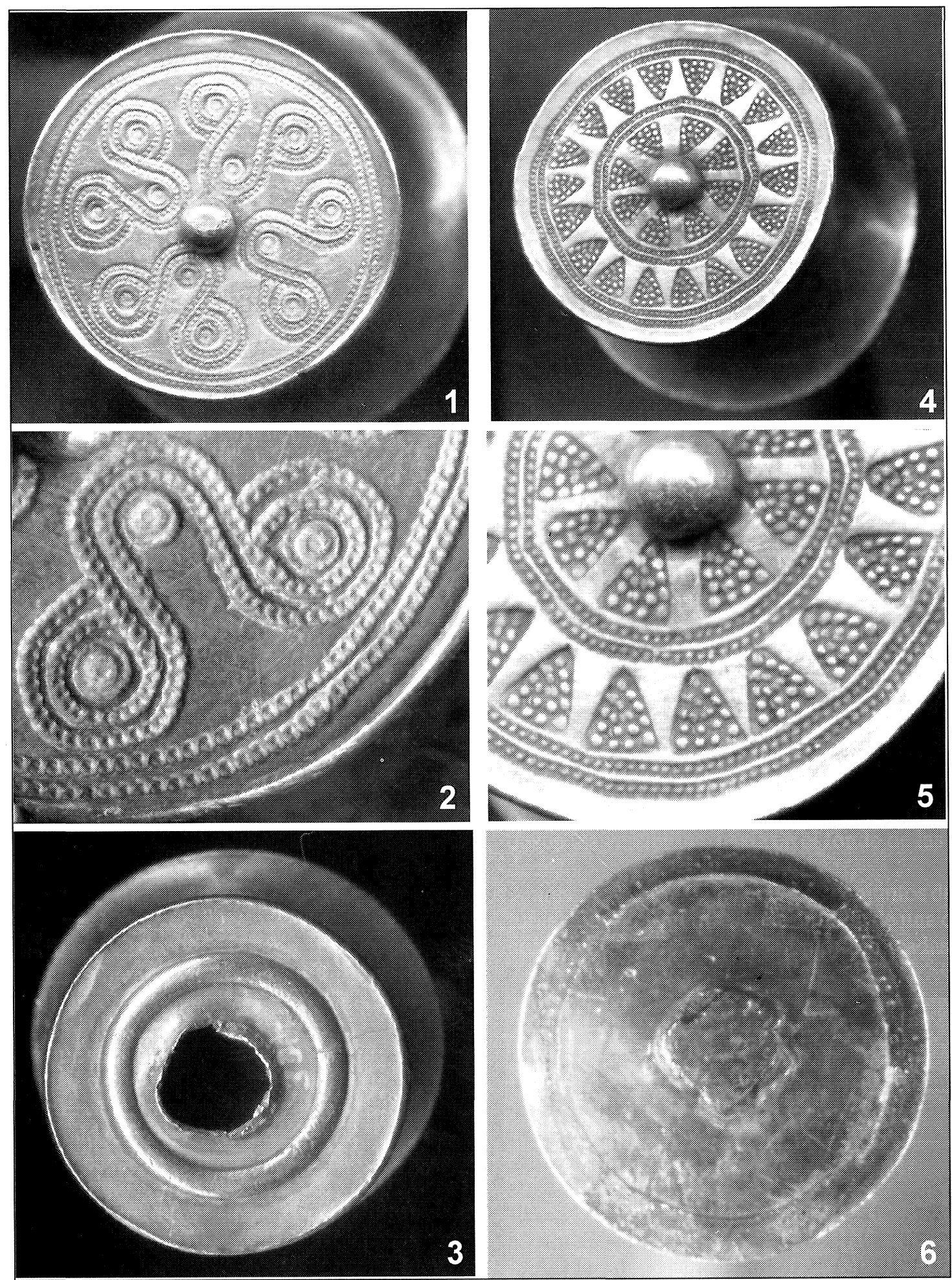

Lám. X. Proceso de fabricación de los terminales 33. 136 (1, 2 y 3) y 33.132 (4, 5, 6); 1. Placa frontal del terminal 33.136; 2. Detalle del empleo de punzones complejos en la decoración de la placa; 3 . Placa posterior con orificio para la entrada del aro; 4 . Decoración de la placa frontal del terminal completo de la pieza; 5 . Detalle del uso de punzones complejos; 6 . Restos de soldadura de la placa posterior del terminal.

T. P., 58, n. $^{\circ} 2,2001$ 

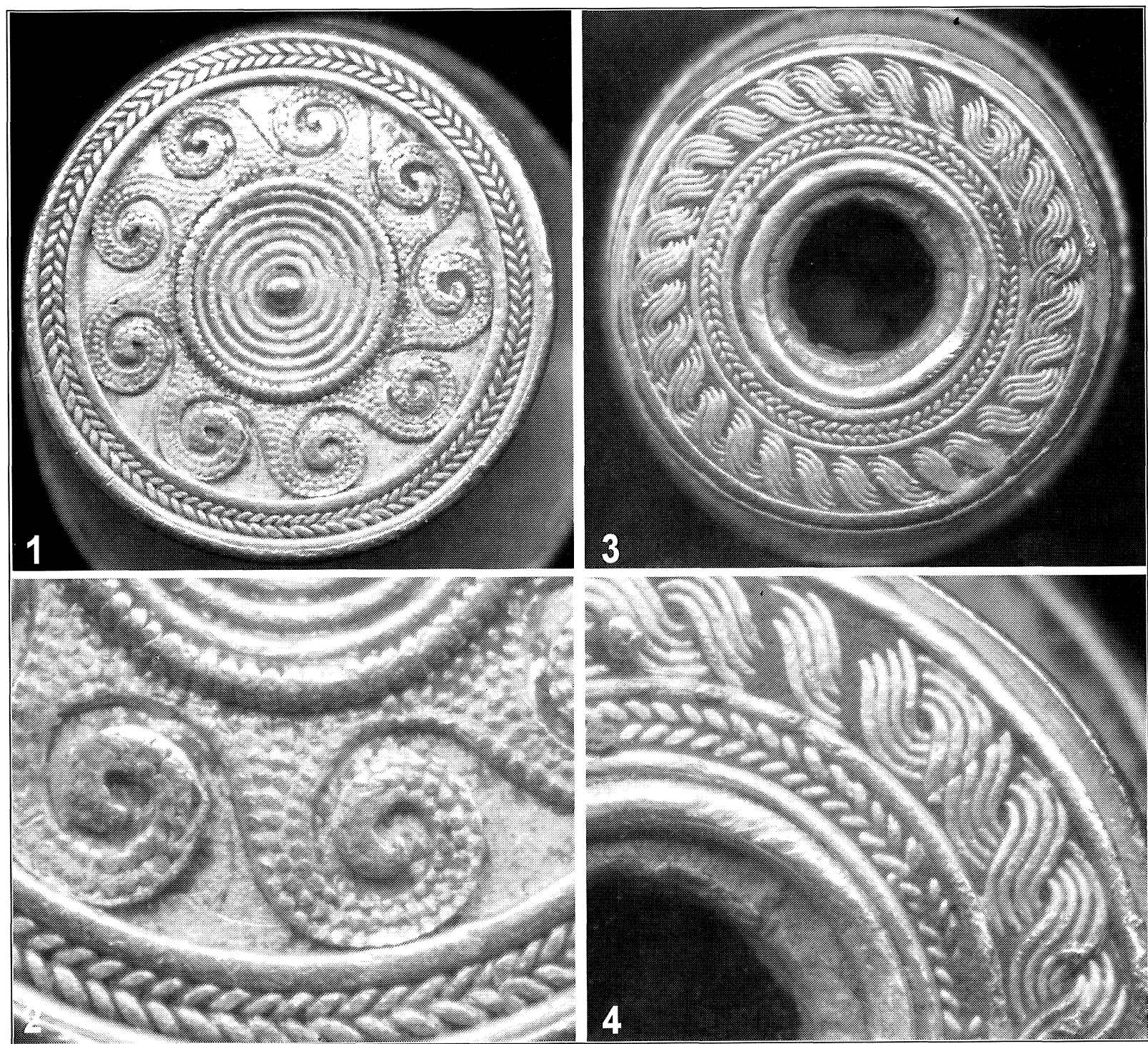

Lám. XI. Detalles de la decoración de las placas frontal y posterior del terminal 33. 138.

salte, simulando un trabajo de filigrana (Lám. XI, 1 y 2 ).

En las placas posteriores la decoración se inicia con una fina banda en resalte a la que sigue un motivo de entrelazado en 8 , continuando hacia la zona central con una nueva banda exenta, otro motivo cordelado y dos bandas en resalte de distinto grosor, que enmarcan el orificio de entrada del aro (Lám. XI, 3).

En el diseño original, realizado sobre material blando previamente a la fundición de las placas, se emplearon varios punzones complejos. Los paralelos formales más cercanos para estas decoraciones pueden encontrarse en piezas como el torques de Langreo, Lebuçao, Vilas Boas o Chaves.

\section{Grupo 2. Diademas-cinturón}

La pieza 33.139 se encontró enrollada sobre sí misma, al igual que los ejemplares del tesoro Bedoya, Elviña o Ribadeo (López Cuevillas, 1951 a: 50-51; Lám. 33). El ejemplar muestra las características básicas de su grupo morfológico, lámina central decorada y sistema de sujeción con anillas en los extremos, pero también rasgos individuali- 
zadores; en este caso un sistema de cierre o sujeción formado por anillas y ganchos (Lám. XII), que ha llevado a algunos autores a interpretarla como gargantilla/diadema (Bóveda, 1999).

Podemos diferenciar dos elementos estructurales: la lámina de base que sirve de soporte a la decoración, y el sistema de cierre o sujeción, situado en los extremos de dicha lámina. No presenta restos de elementos ornamentales plásticos.

Lámina de Base: tiene un grosor mayor que el resto de las diademas-cinturón castreñas, lo que no impide su extrema fragilidad, por lo que descartamos su utilización sin la existencia de un soporte flexible, como cuero o tela.

Este cuerpo central se fabricó a partir del recorte de una fina lámina de oro con forma rectangular y esquinas suavizadas, ligeramente redondeadas, siendo esta característica más acusada en el lateral con ganchos. El recorte se realizó con una herramienta de tipo zizalla, cuyas huellas se suavizaron retocando los bordes de la lámina mediante martillado o batido. Probablemente se realizó un primer pulido de la superficie antes de proceder a su decoración.

La ornamentación se realizó por estampado desde el reverso; los motivos se disponen en ocho bandas longitudinales; desde el exterior, comienzan con una serie de estampaciones en forma de $\mathrm{S}$, una de motivos semiesféricos en resalte y una nueva serie de $\mathrm{S}$ similar a la primera.

En la zona central presenta dos bandas de motivos semiesféricos en resalte, que alternan motivos de forma lisa y otros con aspa central. Siguen a estas series una de motivos en S, otra de motivos semiesféricos y una nueva de S (Lám. IV).

En cada uno de los extremos de estas series, a modo de remate, se disponen cuatro motivos semiesféricos, realizados con dos punzones de diferente tamaño, en disposición triangular, seguidos de dos series de motivos semiesféricos dispuestos en arco, que enmarcan la composición central: la primera se realizó con un punzón similar al empleado en las series longitudinales $n .^{\circ}$ dos y siete, con 16 y 17 motivos respectivamente, la segunda, con motivos en S, presenta una disposición más irregular, con nueve estampaciones en cada uno de los laterales (Lám. XII).

Tanto las huellas de trabajado y la disposición de los motivos indican el uso exclusivo de matrices simples; podemos identificar cuatro punzones diferentes, uno con punta en forma de S (Lám. XIII, 1) y tres con punta semiesférica convexa, uno grande, uno pequeño y un tercero que presenta un aspa o cruz en resalte (Lám. XIII, 2). Tras el estampado de la decoración, la lámina recibió un pulido de acabado.

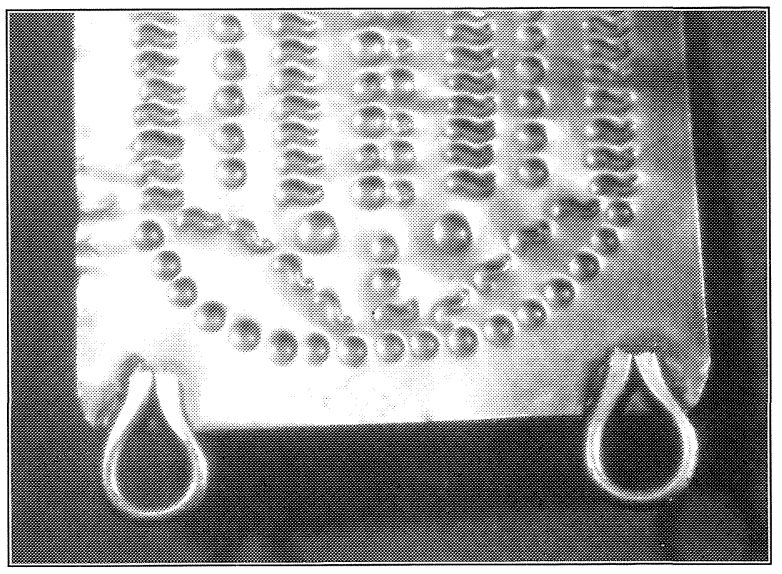

Lám. XII. Diadema-cinturón 33.139. Sistema de cierre con anillas en uno de los extremos. Reverso.

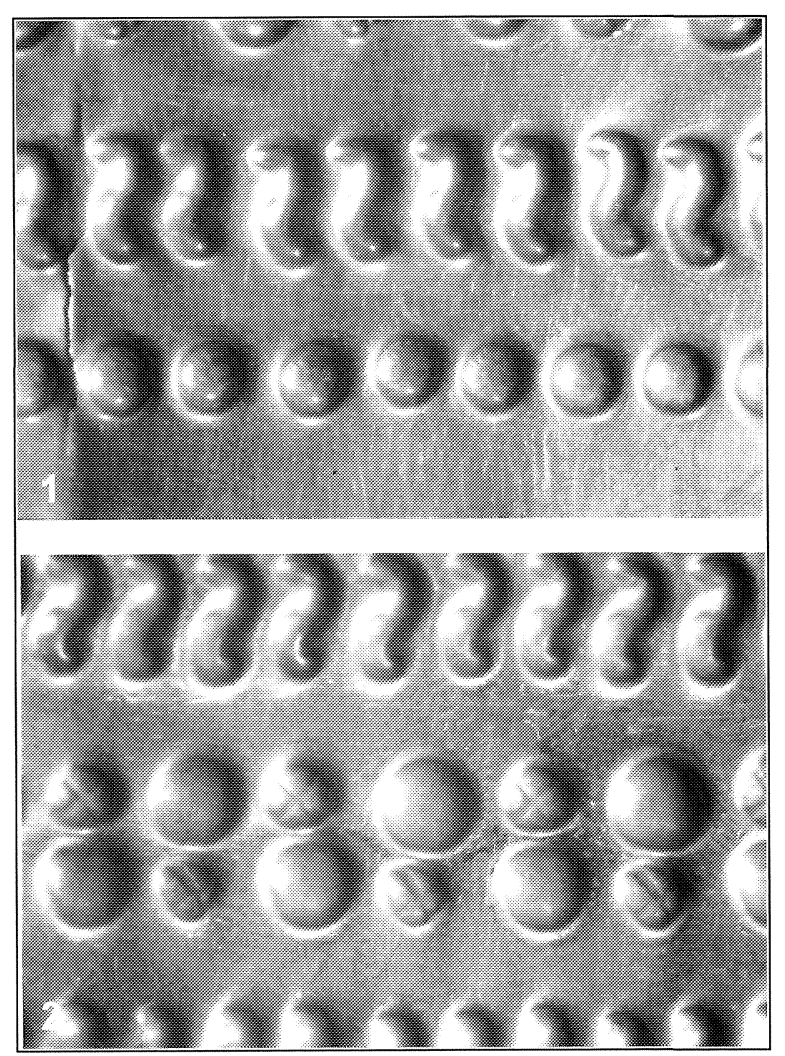

Lám. XIII. Diadema-cinturón 33.139. Detalle de huellas de estampado. Reverso. 
El uso de este tipo de matrices simples es común a todas las diademas-cinturón castreñas; puede observarse, por ejemplo, en la decoración del conjunto de Moñes, formando el fondo acuático y ciertos detalles de las escenas representadas (García Vuelta y Perea, 2000); las estilizaciones de ornitomorfos, también presentes en otros elementos de la plástica castreña (Pérez Outeiriño, 1989), pueden encontrarse en los ejemplares del tesoro Bedoya (Balseiro, 1997), Elviña (Luengo, 1979) o Vega de Ribadeo (López Cuevillas, 1951 b).

Sistema de cierre o sujeción: difiere de los del resto de las diademas-cinturón castreñas, normalmente realizados mediante dos o más anillas con diversa morfología y técnicas de fabricación. En este caso, está formado por una pareja de ganchos de alambre con sección circular unidos a uno de los extremos de la lámina y una pareja de anillas de alambre con la misma sección en el otro. Estos cuatro elementos se soldaron por el reverso de la lámina de base. Para facilitar este proceso, sus extremos fueron aplanados mediante martillado (Lám. XIV, 1 y 2). Esta zona ha sido reparada en época moderna, por lo que la determinación del material soldante es compleja. No podemos, por tanto, determinar la naturaleza de la soldadura original, aunque probablemente se utilizó una aleación ternaria de $\mathrm{Au}$ $\mathrm{Ag}-\mathrm{Cu}$.

Los únicos estudios analíticos realizados sobre el conjunto los aporta A. Hartmann (1982). Según este autor, la lámina central tiene una composición de: c.a $12 \% \mathrm{Ag}$; c.a. $18 \% \mathrm{Cu} ; 0,005 \% \mathrm{Sn}$ y $0,10 \% \mathrm{Pt}$, con impurezas no significativas de Ni y $\mathrm{Zn}$; quedando integrada en el mismo tipo de oros que el torques n. ${ }^{\circ} 33.133,37$ y 38 de este mismo conjunto.

Presenta una fractura en la lámina de base, que prácticamente divide la pieza y ha sido reparada con soldadura blanda de estaño y material de fijación por el reverso; podemos observar algunas pequeñas grietas en su superficie, así como una perforación circular que afecta a uno de los motivos estampados. Gran parte de la superficie de la lámina presenta rubefacción, principalmente en su reverso.

\section{CONCLUSIÓN}

Estas piezas suponen un buen exponente del nivel técnico y las características de las producciones en oro castreñas durante la II Edad del Hierro, per-

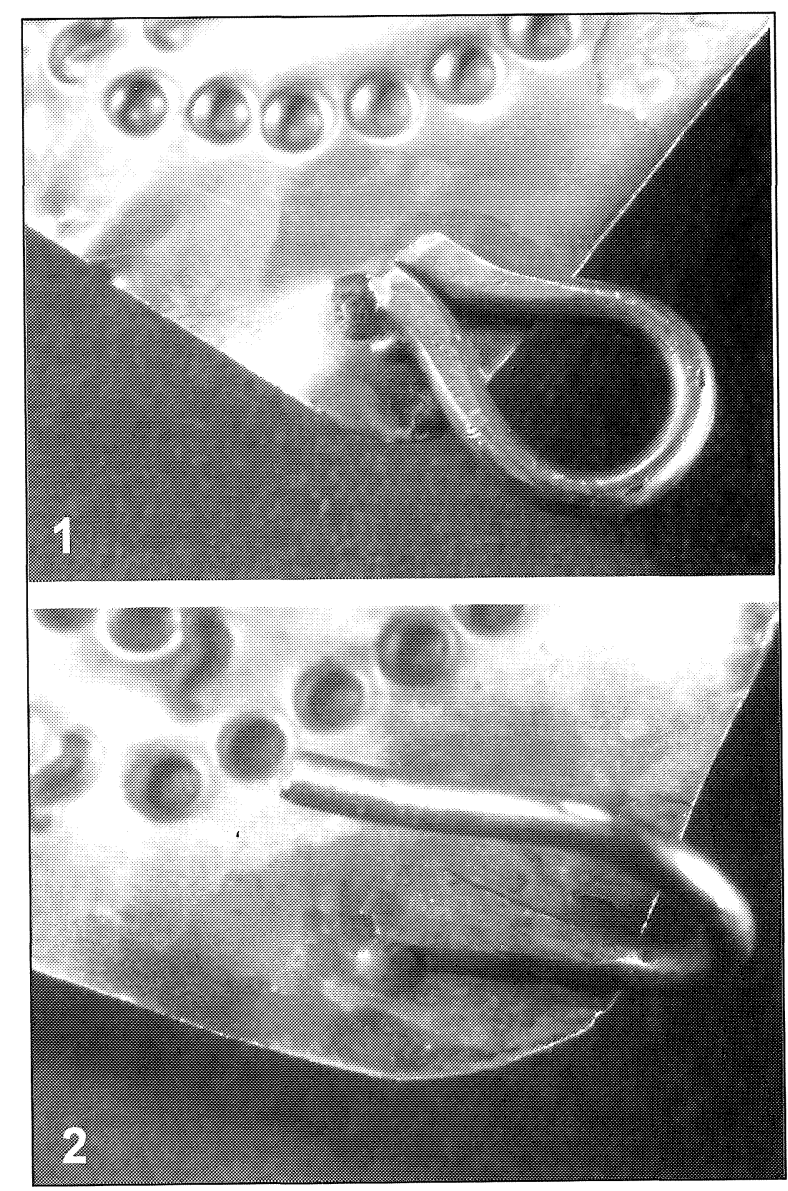

Lám. XIV. Diadema-cinturón 33.139. Detalles de las anillas (1) y ganchos (2) del sistema de cierre. Reverso.

mitiendo una aproximación, desde el terreno de la arqueometalurgia, al momento tecnológico de estas poblaciones.

Aunque los datos documentales expuestos no permiten confirmar su asociación original, los torques del lote de Cangas de Onís presentan una gran uniformidad tipológica y técnica, aunque con algunos rasgos individualizadores, como ya se ha expuesto, quedando plenamente integrados en las producciones del grupo Norteasturiano y perteneciendo con probabilidad -en el sentido amplio del término-, a un mismo taller de fabricación.

Es evidente esta relación en piezas como los terminales del torques $33.132 \mathrm{y} \mathrm{el} \mathrm{n.}{ }^{\circ} 33.136$, similares en la ejecución de sus elementos estructurales y ornamentales, o en ciertos detalles técnicos, como los orificios de expansión de gases en todos los remates. Otras asociaciones entre piezas, como el fragmento de varilla de alambres enrollados 
33.134 con los fragmentos soldados 33.135 , deben aún confirmarse con un adecuado estudio analítico. La interpretación del conjunto, a falta de nuevos datos, queda abierta; a partir de los datos constatables, podemos establecer varias hipótesis de interpretación:

- Observamos restos de, al menos, tres torques, quizá cuatro. Muchas de las huellas observables en la superficie del metal indican que al menos una parte de ellos fueron intencionalmente fragmentados e inutilizados antes de su ocultación o depósito, como queda confirmado por las numerosas marcas de extracción de metal, huellas de corte y fracturas con factura antigua observadas. Esta característica podría dar lugar a una interpretación de estas piezas como acumulación de material de valor.

- Evidencias técnicas, como las extracciones de metal, intentos de corte, estampaciones, retoques por martillado y probablemente también la soldadura presente en el fragmento de varilla 33.135, podrían confirmarse como restos de pruebas técnicas -y no de reparaciones- realizadas sobre las piezas. Este conjunto de datos podría apuntar a una segunda interpretación como un depósito de orfebre, con piezas probablemente destinadas a la refundición, sobre las que se realizaron, además, diversas pruebas de trabajo.

Una tercera hipótesis resume las dos anteriores, presentando el lote de Cangas de Onís como un grupo de piezas con diferente interpretación; que incluye parte de un depósito de orfebre y restos de uno varios hallazgos u ocultaciones de material de valor, con características desconocidas.

En cualquier caso las piezas que integran este lote son un claro exponente del nivel tecnológico y las características técnicas de la orfebrería astur, su estudio supone un claro ejemplo de los problemas que plantea la investigación en arqueología del oro castreño, así como de la gran complejidad de su interpretación. Los problemas planteados por estas piezas, aún sin solución definitiva, reflejan la necesidad de realizar una sistematización documental, contextual y tecnológica de estas producciones como paso previo a su inclusión en el discurso científico.

\section{BIBLIOGRAFÍA}

Álvarez-Ossorio, F. (1931): Adquisiciones del M.A.N. Lote de Joyas Posthallstáticas procedentes de Cangas de Onís. Nota descriptiva. MuseoArqueológico Nacional. Madrid.

T. P., 58, n. ${ }^{\circ} 2,2001$
- (1954): Tesoros Españoles Antiguos en el Museo Arqueológico Nacional. Madrid.

Armbruster, B. y Perea, A. (2000): "Macizo/hueco, soldado/fundido, morfología/tecnología. El ámbito tecnológico castreño a través de los torques con remates en doble escocia". Trabajos de Prehistoria, 57 (1): 97 114.

Balseiro García, A. (1994): El oro prerromano en la provincia de Lugo. Diputación Provincial de Lugo. Lugo.

- (1997): "Aproximación a la orfebrería castreña. El tesoro Bedoya". En V. Alonso Troncoso (ed.): Ferroterra Galaico-Romana. El Ferrol: 49-67.

- (1999): "Problemática del estudio de la orfebrería prehistórica del noroeste peninsular". II Congreso de Arqueología Peninsular (Zamora 1996), III: 19-23.

- (2000): Diademas áureas prerromanas. Análisis iconográfico y simbólico de la diadema de Ribadeo-Moñes. Diputación Provincial de Lugo. Lugo.

Blanco FreiJeiro, A. (1957): "Origen y relaciones de la orfebrería castreña". Cuadernos de Estudios Gallegos, XII (36): 5-28, 137-157 y 267-301.

Bouza Brey, F. (1965): "Tres torques áureos de Galicia". Cuadernos de Estudios Gallegos, XX (60): 5-11.

BóvedA Fernández, M.J. (1999): “As diademas castrexas de Galicia". Actas do congresso de proto-historia europeia. Revista de Guimaraes: 603-616.

Castro Pérez, L. (1998): The sacred torcs. Prehistory and Archaeology of a Symbol. Edimburgo.

CARdozo, M. (1942): “Una pieza notable de la orfebrería primitiva". Archivo español de Arqueología, 15: 93103.

Diego Somoano, C. (1960a): "La Colección "Soto Cortés" de Labra. Cangas de Onís”. Boletín de Estudios Asturianos, 40: 269-291.

- (1960b): "La Colección "Soto Cortés" de Labra. Cangas de Onís". Boletín del Instituto de EstudiosAsturianos, 41: 440-452.

García Vuelta, O. (e.p.): «La colección de orfebrería castreña del Museo Arqueológico Nacional: notas para el estudio de su evolución». Boletín del Museo Arqueológico Nacional, XVIII (2000).

García Vuelta, O. yPerea, A. (e.p.): "Las diademas-cinturón castreñas: el conjunto con decoración figurada de Moñes (Piloña, Asturias).Archivo Español deArqueología, 74 (2001).

Hartmann, A. (1982): Prähistorische Goldfunde aus Europa 2. Spektralanalysche Untersuchungen und deren Auswertung. Studien zu derAnfängen der Metallurgie. Berlín.

LAdra Fernández, L. (1997-1998): “Ouros no desterro: notas encol de dous conxuntos inéditos de ourivesaria castrexa actualmente depositados no MAN". Boletín do Museo Provincial de Lugo, 8 (1): 45-78.

- (1999): "Análisis ponderal de los torques castreños". Complutum, 10: 143-156.

López Cuevillas, F. (1951a): Las Joyas Castreñas. Madrid. 
- (1951b): "La diadema áurea de Ribadeo". Cuadernos de Estudios Gallegos, 6: 23-31.

LuENGo MARTínez, J.M. (1979): "El tesoro de Elviña y tres torques coruñeses". Trabajos de Prehistoria, 36: 213246.

Marco Simón, F. (1994): "Heroización y tránsito acuático: sobre las diademas de Moñes (Piloña, Asturias)". En J. Alvar y J. Mangas (eds.): Homenaje a José María Blázquez, II: 319-348.

MAYA GonZÁlez, J.L. (1987-88): La cultura material de los castros asturianos. Estudios de la Antigüedad, 4-5. Universidad Autónoma de Barcelona. Barcelona: 127. 138.

Maya González, J.L. y Cuesta Toribio, F. (1993): "Indigenismo y romanización". Origenes: Arte y Cultura en Asturias. Lunwerg. Barcelona: 11-49.

Moteagudo, L. (1952): "Torques castreños de alambres enrollados". Archivo Español de Arqueología, XXV: 287-296

Perea, A. y Sánchez-Palencia, F.J. (1996): Arqueología del Oro Astur. Orfebrería y Minería. Caja de Asturias. Oviedo.

Pérez Outeiriño, B. (1980): "Os ornitomorfos no conxunto dos motivos decorativos da orfebrería castrexa”. Boletín Auriense, X: 9-24.

- (1990): "Achega tipológica para o estudo dos torques aureos do N.O." Gallaecia, 12: 139-151.

Prieto Molina, S. (1996): "Los torques castreños del Noroeste de la Península Ibérica". Complutum, 7: 195223.

RadDATz, K. (1969): Die schatzfunde der Iberischen Halbinsel. 2 vols. Berlin.

Reboredo Canosa, N. (1996): "El tesoro de Elviña". El Oro y la Orfebrería Prehistórica de Galicia. Museo Provincial de Lugo. Diputación Provincial de Lugo. Lugo: 71-87.

VV.AA. (1989): El oro en la España Prerromana. Revista de Arqueología. Madrid.

VV.AA. (1996): El oro y la orfebrería prehistórica de Galicia. Diputación Provincial de Lugo. Lugo. 